\title{
Exploring the Effects of Hope on GPA and Retention among College Undergraduate Students on Academic Probation
}

\author{
Holly Seirup and Sage Rose \\ Department of Counseling, Research, Special Education, and Rehabilitation, Hofstra University, 160 Hagedorn Hall, Hempstead, \\ NY 11550, USA \\ Correspondence should be addressed to Holly Seirup, holly.seirup@hofstra.edu
}

Received 15 September 2010; Revised 25 January 2011; Accepted 18 March 2011

Academic Editor: Eric Z. F. Liu

Copyright (๑) $2011 \mathrm{H}$. Seirup and S. Rose. This is an open access article distributed under the Creative Commons Attribution License, which permits unrestricted use, distribution, and reproduction in any medium, provided the original work is properly cited.

\begin{abstract}
This study analyzed the impact of hope on the academic achievement and retention of 235 students on academic probation at a private Northeastern university. Probationary students were enrolled in a mandatory online course designed to facilitate academic and nonacademic skills, to improve student GPAs and overall retention. The Hope Scale (Snyder et al. (1991)) was administered to identify whether students with greater levels of hope would experience an increase in academic success upon completion of the course. Students were broken down into groups of high, medium, and low hope based on their scores on the instrument. Results showed students who completed the course were more likely to be retained than those who did not complete the course, had a slight increase in GPA by the end of the semester, and high-hope students showed the greatest overall gain in GPAs.
\end{abstract}

\section{Introduction}

The National Center for Educational Statistics [1] report that 18.4 million students were enrolled at two- and four-year postsecondary institutions in the fall of 2009. These students started their undergraduate education after completing an exhaustive search and selection process, to find the school they consider to be the right "fit." Yet 26\% of first year students enrolled in a four-year college or university will leave without completing a degree [2]. Despite this statistic, students and institutions generally have high expectations of academic success given the amount of time and money spent on the college search process by the student, and the recruitment/admissions procedure on the part of the institution. Great care is made to review high school records, extracurricular involvement, and standardized test scores to ensure that the student fits the academic profile of a potential graduate. It is anticipated that students will attend their courses, will be able to maintain the required academic rigor, and graduate in a timely manner. However, at some point during their college careers, $25 \%$ of all students will be on academic probation [3]. Pascarella and Terenzini [4] state that "even given their limitations. ..college grades may well be the single best predictors of student persistence, degree completion, and graduate school enrollment" (p. 396). Ishitani and DesJardins [5] found an inverse relationship between a student's first year GPA and their likelihood of dropping out of college. Therefore, grades, academic performance, and probationary status are important factors to consider when developing academic support initiatives to facilitate persistence and retention among college student populations.

1.1. Characteristics of Probationary Students. Research reveals that students on academic probation typically earn less than a $\mathrm{C}$ grade point average [6], have poor academic preparation $[7,8]$ and inadequate time management skills [9-11], lack study skills $[12,13]$, and have difficulty in transitioning and adjusting to college life $[9,14]$. Probationary students also exhibit lower levels of motivation $[14,15]$ and demonstrate an external locus of control $[3,9,13]$ impacting their beliefs about how much control they have in improving their academic situations. "When students are faced with academic demands, the way they approach academic tasks and view themselves can play a significant role in their academic success" [14] (pp. 468). 
Students on academic probation may find themselves caught in a cycle in which their academic workload continues to increase while they lack the study and time management skills needed to find balance among their course demands. Furthermore, when they do obtain a low test score or failing grade, probationary students externalize this negative evaluation rather than use it to inform their future actions and decision-making processes. Research reveals that these students are also less likely to seek out needed assistance $[11,14,16]$. In addition to problems with adequate planning, many probationary students struggle with creating and maintaining academic goals as well as future oriented career goals $[10,14,17,18]$. Inabilities to initiate and manage proximal and distal goals have a tremendous impact on the likelihood of academic success [19]. In a report by the American College Testing (ACT) organization [20] it was noted that "students who master course content but fail to develop adequate academic self-confidence, academic goals, institutional commitment, and social support and involvement may still be at risk of dropping out" (p. 10).

Numerous interventions have been designed and implemented in an effort to support probationary students. Interventions range from those that are more voluntary to those that are mandatory "in an attempt to "force" students to help themselves" [21] (pp. 5). Required interventions (or intrusive programs) may include developing contracts with students, requiring supervised study time, individual and group counseling, and meetings with academic advisors. Often these intrusive programs/advisement models are put in place to assist students on academic probation who might not otherwise seek assistance [11, 15, 21]. Voluntary or nonintrusive interventions offer assistance by way of advisory meetings, inviting students to attend specially designed programs, workshops, and seminars. Voluntary or involuntary, these interventions are designed to return students to a successful academic standing in a timely manner. Despite the best intentions of these interventions, students must value the information and strategies provided, have an expectation that they will improve their academic circumstances and assist them in reaching their academic goals. Interventions typically provide concrete methods that maximize behavioral effectiveness in studying, time management, and engagement in class; however, students must see these as viable routes that will help in areas where they are struggling academically. According to theories of positive psychology, individuals need to believe that success is a possibility in order to engage in strategies, overcome obstacles, and achieve valued goals [22]. This study utilizes the framework of hope theory [23], a member of the positive psychology family, to investigate how perceptions of success affect achievement among college students participating in an academic intervention.

1.2. Hope. Hope is defined as a motivational belief system that affects goal setting behaviors and perceptions about future success [23]. Research has shown that adolescents and adults with high levels of hope perform better in school, athletics, maintenance of healthy lifestyles, problem-solving behaviors, and experience positive psychological well-being [24]. Hope affectively impacts so many life domains because high-hope individuals are better able to set effective goals and make good decisions about these goals. According to Snyder et al., [23] individuals with high hope can clearly define goals, produce strategies to obtain those goals (pathways), and sustain the volitional thought needed to use multiple strategies (agency) when motivation towards goals subsides. Goals are important to hope because they provide the anchor system in which pathways and agency perceptions are directed. High-hope individuals as compared to low-hope individuals are more likely to conceive alternative pathways when obstacles arise and can maintain regulation over negative emotions $[23,25]$. Agency and pathways are both equally necessary in goal attainment and when one part of that system wanes, it impacts the other. Snyder et al. [26] agree that even the best strategies can fail if the belief that one can be successful is not there. Individuals tend to maximize their agency thoughts through the use of positive selfstatements like "I meet the goals that I set for myself" (see Dispositional Hope Scale; [23]) and pathways perceptions thrive when there are multiple options available. Individuals high in hope are able to maintain sight of their goals and track their progress in achieving them.

Individuals with high hope have been shown to be highly effective in performing well in educational contexts. Scores on hope measurement have been found to be predictive of academic achievement across all grade levels. Hope scores predict achievement outcomes across multiple student levels. Scores on hope measurement significantly predicted elementary students' achievement test scores [22, 27], as well as higher scores on the Iowa Test of Basic Skills even when locus of control and self-worth were controlled for [22]. Hope scores have predicted junior high and high school students' grade point averages (GPAs) [23, 28], and higher semester and overall GPAs for college students [2931]. Additional studies indicate that scores on the DHS predict student coping and adequate study skills [32], the maintenance of goals in difficult academic situations and completing a college degree [33]. Based on this literature, it appears that hope would play a large role in how effectively students on academic probation would benefit from university intervention if their goal was academic improvement.

1.3. Purpose. It is through the lens of hope theory that we investigated factors affecting students on academic probation. The participants in this study were those students enrolled in a course specifically designed to promote academic success. We investigated whether this course could serve as an adequate intervention to increase the GPA of college undergraduates placed on probation and if hope affected this particular population's GPA.

\subsection{Research Questions.}

(1) Will there be significant changes in GPA after students have completed the academic success course? 
(2) Is hope a significant predictor of GPAs among students on academic probation?

(3) Will completion of the academic success course have an impact on student retention?

\subsection{Hypotheses.}

(1) There will be a significant increase in GPA after students have completed the academic success course.

(2) Students higher in hope scores will have higher end of semester GPAs than students low in hope scores.

(3) Completion of the academic success course will show an increase in student retention.

It was anticipated that the course would expose students to positive academic and nonacademic skills that could promote student gains in GPA and reduce the amount of students on academic probation. Specifically through this instruction, students could improve their academic agency and accumulate multiple academic pathways that they could use when they were faced with obstacles to their own achievement.

\section{Methods}

2.1. Intervention Framework. In an effort to provide support for students on academic probation, a private university in the Northeast developed an intrusive program, which sought to combine factors from both mandatory and voluntary interventions. This was done by creating an online course that was required for students to successfully complete the first semester (15 weeks) in which they were on academic probation. The online course consisted of topics compiled from workshops that have been used within common voluntary intervention programs. The university's senate approved a recommendation to develop the course titled UNIV 01: Academic Success. UNIV 01 was designed for probationary students' development and enhancement of skills necessary for academic and future success. The university bulletin stated that all students placed on probation will be required to take a course on strategies for academic success for one semester hour of nonliberal arts credit. The course would assist students in developing and/or strengthening "nonacademic" factors such as study and time management skills, test-taking strategies, and a broader understanding of university resources. The course also offered information related to financial aid, relationships, and mental health issues and a review of various contemporary issues that often impact student success. The course was an online, asynchronous course that was self-paced and could only be taken on a Pass/Fail basis. The course had to be successfully completed and passed before the student could register for the following semester.

The structure of UNIV 01 was designed so that there were 10 separate modules presented sequentially and students must successfully complete each module before moving on to the next. Multiple and diverse teaching methods were employed throughout the course. Prior to the course being implemented, the instructor developed power points, exercises, and assignments related to the topic being taught in each module. The instructor's lecture was digitally recorded and all of this related course material was uploaded into Blackboard, the learning management system (LMS) at the university. Each module included a video lecture, power point, exercises, various assignments (such as readings, short papers, and surveys) and a posttest to assess content knowledge. Students learned the best methods to balance personal issues, social lives, work roles, and course requirements with the necessary behaviors to be academically successful. Because the focus was on building skills to facilitate a sense of confidence in their educational performance, or academic agency, one particular assignment was the completion of the Dispositional Hope Scale (DHS) [23]. This instrument was chosen because it shares characteristics with a multitude of other measures of motivation, adaptive functioning, problem-focused coping, and physical well-being [26] and shares the commonalities with Tinto's theory [8] that educational and occupational goals are important for student success.

2.2. Participants. The sample consisted of 235 undergraduate students on academic probation from a Northeastern university. Each student was enrolled in the UNIV 01 course during the 2008-2009 academic year. Of those enrolled in the course, $62 \%$ were Caucasian, $71 \%$ were male, and $29 \%$ female. A majority of the students were freshman $(35 \%)$, sophomores $(39 \%)$, and juniors $(23 \%)$ with very few seniors $(3 \%)$.

2.3. Materials. A survey containing 44 self-report items was designed for this course (with the assistance of the Department of Institutional Research). The items asked students to report how often they did the following: missed class, activities involvement (clubs and programs), used available academic resources (writing center, tutoring, and libraries), used self-regulation (knowledge of study skills and time management), talked with support systems (friends, family, and faculty at the university), actual time spent studying, time spent working (on and off campus), internet use for academics, and internet use for entertainment. The institutional survey has demonstrated low reliability $(\alpha=$ .43) largely due to the multiple self-report items that vary in report style and topic. Despite the low reliability of the institutional survey, the self-report information was used to identify relationships with other measures used in the study.

2.3.1. Dispositional Hope Scale. The Dispositional Hope Scale (DHS) contains four pathway items (e.g., "I can think of many ways to get out of a jam"), four agency items (e.g., "My past experiences have prepared me well for my future"), and four distracter items (e.g., "I feel tired most of the time") [23]. Participants rate how well the item describes them on an 8-point Likert scale $(1=$ definitely false, 8 = definitely true). The DHS score is computed by adding the pathways and agency items, which have been found to correlate positively with each other. The DHS has sufficient internal reliability with an alpha ranging from .74 to .84 , and test-retest samples provide evidence for the temporal 
stability of the measure over 10-week intervals: .76 and .82 , respectively, $P<.001[23,34]$.

2.3.2. Grade Point Average (GPA). For the purposes of this study, Grade Point Average (GPA) was an average of a student's final grade in each course they completed based upon a 4.0 scale. A 4.0 would equate to a letter grade of $\mathrm{A}$; a 3.0 to a letter grade of $\mathrm{B}$; a 2.0 a letter grade of $\mathrm{C}$; a 1.0 a letter grade of D; a 0.0 a letter grade of F. GPA is considered a measure of academic achievement. Anything under a 2.0 would be considered below average and would place a student on academic probation. The authors received a list of beginning of semester GPA and end of semester GPA for each student enrolled in UNIV 1 from the Office of Academic Records for the purpose of this analysis.

For the purposes of this study retention will be measured by whether or not the student is enrolled for the semester after completing the UNIV 1 course.

2.4. Procedure. The UNIV 01 course was developed to provide academic and nonacademic support and reinforce the availability of campus resources for students placed on academic probation. Rationale for the course stemmed from the awareness that students on academic probation are more likely to drop out. Furthermore, typical students "at risk" are often identified at the point of admission, which is based upon student being identified as those who are "ethnic minorities, academically disadvantaged, have disabilities, are of low socioeconomic status ..." [16]. At-risk students are often "academically underprepared" or those who are "first in the family to go to college" [35], (pp. 555). Because of these disadvantages, many universities provide at-risk students with additional support services through supplemental instruction, tutoring, and academic support built into various programs. This course (UNIV 01) was designed for students who do not necessarily fit the typical construct of being "at risk" and therefore did not initially receive additional academic support yet these students may not have clear knowledge of how to be successful at college. After a minimum of one semester these students were identified as struggling academically with a cumulative GPA of 2.0 or lower. This GPA puts them in a new at-risk category of dropping out and not being retained.

UNIV 01 was offered as a pilot in the fall of 2007 to first year students who completed their first year with a GPA under a 2.0. In the spring of 2008 semester, any first, second, or third year student who was on academic probation and had not taken the course previously was automatically registered for the course. Each student enrolled had to complete the pre- and postcourse survey, 10 modules, and five assignments. In the fall of 2008, the researchers added the Dispositional Hope scale as one of the assignments. Students were asked to complete an online informed consent form and had an optional assignment if they chose not to participate.

\section{Results}

To address our first research question and hypothesis, a $t$ test was performed showing a significant difference $(t(233)=$
$-8.75, P<.01)$ between beginning of semester GPA $(M=$ $1.67, \mathrm{SD}=.41)$ and end of semester GPA $(M=1.93, \mathrm{SD}=$ .39) indicating that students' cumulative GPA increased upon completion of UNIV 01. Addressing research question and hypothesis (2), we investigated the impact hope scores had on GPA. To do so, students were categorized as being high, medium, or low hope by partitioning DHS scores into three equal groups. These groups were broken apart by the distribution of students' total hope scores (see Table 1 for mean hope scores). Creating high, medium, and low groups based on hope score is a typical method to identify how these classifications differ academically and has been supported in past research [36]. Once students were grouped, we performed a one-way analysis of variance (ANOVA) on beginning semester GPAs by student hope level. Students did not differ significantly in GPA by the level of hope they possessed at the beginning of the semester, $F(2,230)=.49$, $P>.05$ (see Table 1 for mean GPAs). To investigate the effect of hope level on end of semester GPA, a one-way analysis of covariance (ANCOVA) was performed with the students' end of semester GPA entered as the dependent variable, the level of hope as the independent variable, and students' prior GPA as the covariate. After adjusting for prior GPA levels, there was a significant effect of hope level on end of semester GPA, $F(2,229)=5.86, P<.05$, partial $\eta^{2}=.05$, with high hope students obtaining significantly higher end of semester GPAs than low and medium hope students (see Table 1). Figure 1 shows the positive trend for UNIV 01 GPA by hope level. Tukey post hoc comparisons of the three hope groups indicate that the high level of hope group $(M=2.03,95 \% \mathrm{CI}$ $[1.94,2.11])$ had significantly higher end of semester GPAs than the low level of hope group $(M=4.43,95 \%$ CI [3.80, 5.61]), $P=.002$. Comparisons between the medium level hope group $(M=1.93,95 \%$ CI $[1.85,2.01])$ and the other two groups were not statistically significant at $P<.05$.

Hope scores were also found to be significantly related to study skills and time management statements $(r=.26$, $P<.01)$ and were negatively correlated with missing class $(r=-.16, P<.05)$ according to responses on the 44 item precourse survey. Hope scores were not significantly correlated with involvement in activities, usage of academic resources, support systems, time working and studying, or internet usage.

To support our third hypothesis, or how student retention was affected given the completion of UNIV 01 , we reviewed institutional data provided by the university. In the past, this Northeastern university found that $80 \%$ of the students who completed the course in 2007 were retained as compared to $31 \%$ who did not complete the course (Institutional Research department, 2009). For the 2008-09 cohort under study, the retention rate of those students who completed the course was $73 \%$ for those who completed the course and $45 \%$ for those who did not complete the course. Although the percentages indicate that those who complete the course are more likely to be retained, there may be other variables not included in this study, (such as the impact of the economy) which may also be impacting student retention. This could be an area to continue to analyze in longitudinally studies in future research. It is important to note that those 
TABLE 1: Student hope and GPA levels prior to and after UNIV 01.

\begin{tabular}{lccc}
\hline & $N$ & $\begin{array}{c}\text { Beginning of semester GPA mean } \\
\text { and standard deviation }\end{array}$ & $\begin{array}{c}\text { End of semester GPA mean and } \\
\text { standard deviation }\end{array}$ \\
\hline Low hope $(M=42, \mathrm{SD}=5.24)$ & 70 & $M=1.65, \mathrm{SD}=.37$ & $M=1.81, \mathrm{SD}=.42$ \\
Medium hope $(M=50, \mathrm{SD}=1.57)$ & 81 & $M=1.66, \mathrm{SD}=.48$ & $M=1.94, \mathrm{SD}=.36$ \\
High hope $(M=57, \mathrm{SD}=2.99)$ & 82 & $M=1.71, \mathrm{SD}=.37$ & $M=2.03, \mathrm{SD}=.38$ \\
\hline
\end{tabular}

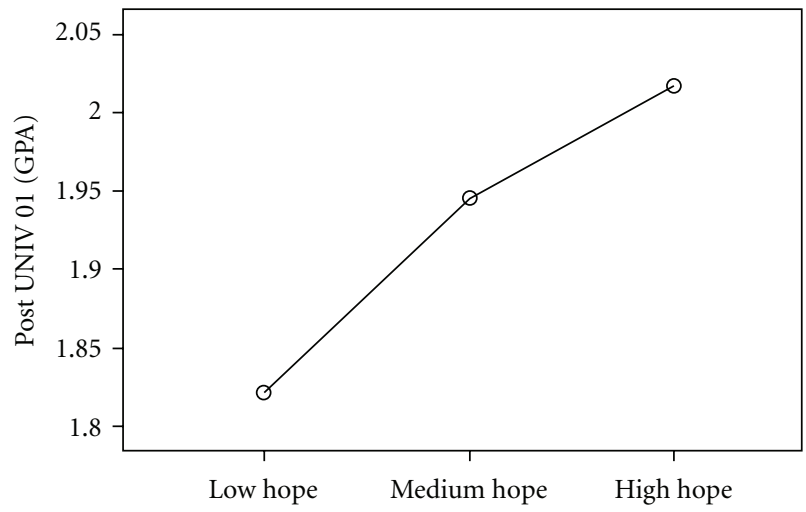

FIgURE 1: Student post UNIV 01 GPA by hope level.

who did not complete the course but who were retained to the following semester needed to re-register and complete the course as a condition of their continuation of their enrollment. More that $50 \%$ of the students who successfully completed and passed the course increased their GPA to a 2.0 or higher. Although this shows a positive trend/outcome, additional longitudinal research is necessary to support this finding.

\section{Discussion}

Students from UNIV 01 showed a significant increase from beginning semester GPA to end of semester GPA. Even though the mean end of semester GPA is still below a 2.0, a majority of the students were retained. This could be because students were provided strategies and tools that supported agency beliefs as well as clear pathways to increase their performance. UNIV 01 was specifically designed to teach positive academic skills and behaviors and help students set reasonable academic goals that could be managed over time, thus encouraging an active orientation toward positive academic behaviors.

While the instruction of appropriate academic behaviors is important, students need to value this information and believe that it will be useful in improving their academic standing. Students who are more hopeful are more likely to engage in self-regulatory behaviors and internalize strategies to obtain their goals of academic success. Within our study, students with higher levels of hope appeared to have slightly higher beginning of semester GPAs however these differences were not statistically significant. According to our ANCOVA, even when controlling for prior GPA, students with higherhope levels showed higher end of semester GPAs. This could be attributed to students internalizing positive strategies in UNIV 01 designed to improve academic success. This provides a starting point to understanding what is happening among this sample of students. In regards to hope theory, our findings may be showing that students with higher levels of hope were better able to make meaning of UNIV 01 material and apply it to their own academic circumstances in a way that resulted in a significant increase in their GPA. This would be in line with past research indicating that students with high hope tend to excel academically above their low hope counterparts [33].

This study adds to current literature by further investigating hope's predictive capabilities among a struggling sample of college undergraduate students. Based on our findings, hope played a significant part in the increase of end of semester UNIV 01 GPA and indirectly impacted student retention. Hope theory specifies that pathways perceptions are influenced by one's learning history and experiences of achieving desired goals. This facilitates agency beliefs and impacts future pathways thinking [37]. Training in specific skills like time management, study behaviors, and building adequate support systems is a way to maximize hopeful beliefs about the future. Students that tend to be hopeful in academic pursuits are more likely to utilize strategies such as managing their time on course work, improving their study skills, and attending class. For students enrolled in UNIV 01: Academic Success, facilitating hopeful pathways was done by reminding students of the availability of academic resources and support; reiterating and/or teaching time management and study skills; reviewing contemporary issues and alternatives that may impact a student's academic success. It may be that in conjunction to providing strategies to increase academic success, student hope should also be addressed through hope-based interventions. It is anticipated that this facilitation of positive belief systems would therefore increase GPA and the probability of these students being retained.

Past hope interventions have been developed to benefit students by instilling hopeful thinking as part of the curriculum or subject matter being taught. According to Lopez et al., [28] to enhance hope levels, educators could focus on the personal statements students use to describe themselves. This may be a simple as reducing negative self-talk or could include more involved methods such as reviewing literary narratives for hopeful representations, studying high-hope individuals in history, and employing hopeful applications in addressing academic challenges. Personal narratives written by students can be especially effective in identifying students 
with low hope, and those who may benefit from an individual intervention. Facilitating hopefulness is a process of helping individuals set relevant subgoals that are seen obtainable, thus promoting energies that will stimulate hope-based cognitions and movement on a pathway toward a larger goal [37]. For students struggling academically, they may need to set subgoals such as studying each night for a difficult course, or drafting a term paper early so they can spend more time editing for mistakes. These subgoals will help them achieve larger distal goals like increasing their cumulative GPA.

While hope interventions can encourage hopeful thinking in students, they also have a place in the overall school environment. Hope-based interventions are also considered cost-efficient and easy to use in current educational institutions. Hope interventions are not limited to students, but teachers and administrators should also be able to display hopeful thinking in order to effectively teach students the best practices. We as educators can maintain a belief system that multiple strategies to success are important, but we also must believe in these strategies in order for them to actually work.

In this study, providing university support to students on probation resulted in increases in the student GPA. Although raising the GPA over a 2.0 for some may take additional semesters, we did identify a positive trend that may be due to hopeful thought processes. Further, retention of students who completed the class was much higher than those who did not, indicating the initial effectiveness of UNIV 01.

There are a few limitations regarding the current study. One possible limitation is that our sample of students took the hope measure once, and therefore we cannot deduce an increase of hope over the span of the course. Future studies will need to include a pre- and postmeasure of hope within the context of academic intervention to determine whether hope increases parallel increases in GPA. In addition, the 44-item self-report measure the university uses to ask general questions about missing class, activities involvement, academic resources, used self-regulation, support systems, and time spent working and studying had very low reliability ( $\alpha=.43$ ) suggesting a low internal consistency. Because the measure is considered questionable in regards to reliability, relationships correlating time management, class attendance, and hope scores should be interpreted with caution. In future studies, other well-established measures of student perceptions should be included to rule out competing theories known to predict academic achievement such as self efficacy, engagement, coping, and goal orientation.

Further, many of these students within our sample came from middle to upper SES backgrounds and may already be much more hopeful than students who experience different types of social constraints or limited academic resources. While hope is considered a construct that is universally beneficial [23] and a theory that benefits students of all backgrounds [22], future research needs to include diverse samples of academically struggling students. Other future research will include conducting a longitudinal study on the impact of hope and the continued academic success of the students in this particular cohort. Keeping track of probationary students' hope over time will indicate whether hope interventions are successful long-term strategies in facilitating academic success and retention.

\section{References}

[1] National Center for Educational Statistics, Fast Facts, US Department of Education, Office of Educational Research and Improvement, Washington, DC, USA, 2009.

[2] American College Testing Service, ACT College Readiness Benchmarks, Retention, and First-Year College GPA: What's the Connection? ACT, Iowa City, Iowa, USA, 2005.

[3] A. Cohen and F. Brawer, The American Community College, Jossey-Bass, San Francisco, Calif, USA, 4th edition, 2002.

[4] E. T. Pascarella and P. T. Terenzini, How Colleges Affect Students: A Third Decade of Research, vol. 2, Jossey-Bass, San Francisco, Calif, USA, 2005.

[5] T. T. Ishitani and S. L. DesJardins, "A longitudinal investigation of dropout from college in the United States," Journal of College Student Retention, vol. 4, no. 2, pp. 173-201, 2002.

[6] E. Tover and M. Simon, "Academic probation as a dangerous opportunity: factors influencing diverse college student success," Community College Journal of Research and Practice, vol. 30, pp. 547-564, 2006.

[7] S. Isonio, "Profile of students on probation/disqualification at Golden West College," ERIC Document, Office of Educational Research and Improvement: U.S. Department of Education, 1995.

[8] V. Tinto, Leaving College: Rethinking the Causes and Cures of Student Attrition, University of Chicago Press, Chicago, Ill, USA, 1993.

[9] M. Balduf, "Underachievement among college students," Journal of Academic Advancement, vol. 20, no. 2, pp. 274-294, 2009.

[10] M. A. Olson, "Characteristics of students on academic probation," Community/Junior College: Quarterly Research and Practice, vol. 14, no. 4, pp. 331-336, 1990.

[11] W. R. Earl, "Intrusive advising of freshman in academic difficulty," NACADA Journal, vol. 8, no. 2, pp. 27-33, 1988.

[12] H. L. K. Coleman and A. M. Freedman, "Effects of structured group intervention on the achievement of academically at-risk undergraduates," Journal of College Student Development, vol. 37, no. 6, pp. 631-636, 1996.

[13] E. T. Pascarella and P. T. Terenzini, How Colleges Affect Students, Jossey Bass, San Francisco, Calif, USA, 2001.

[14] P. Hsieh, J. R. Sullivan, and N. Guerra, "A closer look at college students: self-efficacy and goal orientation," Journal of Advance Academics, vol. 18, no. 3, pp. 454-476, 2007.

[15] R. Abelman and A. Molina, "Style over substance revisited: a longitudinal analysis of intrusive intervention," NACADA Journal, vol. 21, no. 1-2, pp. 32-39, 2001.

[16] D. L. Heisserer and P. Parette, "Advising at-risk students in college and university settings," College Student Journal, vol. 36, no. 1, pp. 69-83, 2002.

[17] J. Cuseo, "Academic advertisement and student retention: empirical connections and systemic interventions," Message posted to First Year Assessment List Serv, 2003, http://www .nacada.ksu.edu/clearinghouse/advisingissues/retain.htm.

[18] V. Gordon and G. Steele, "Undecided first-year students: a 25year longitudinal study," Journal of The First-Year Experience \& Students in Transition, vol. 15, no. 1, pp. 19-38, 2003. 
[19] A. Bandura, "Self-efficacy: toward a unifying theory of behavioral change," Psychological Review, vol. 84, no. 2, pp. 191-215, 1977.

[20] V. A. Lotkowski, S. B. Robbins, and R. J. Noeth, "The role of academic and non academic factors in improving college retention," ACT Policy Report, ACT, Iowa City, Iowa, USA, 2004, http://www.act.org/research/policy/index.html.

[21] R. Damacheck, "Support programs for students on academic probation," Office of Educational Research and Improvement: U.S. Department of Education ERIC Document, 2003.

[22] C. R. Snyder, J. Cheavens, and S. C. Sympson, "Hope: an individual motive for social commerce," Group Dynamics, vol. 1, no. 2, pp. 107-118, 1997.

[23] C. R. Snyder, C. Harris, J. R. Anderson et al., "The will and the ways: development and validation of an individual-differences measure of hope," Journal of Personality and Social Psychology, vol. 60, no. 4, pp. 570-585, 1991.

[24] S. J. Lopez, C. R. Snyder, J. L. Magyar-Moe et al., "Strategies for accentuating hope," in Positive Psychology in Practice, P. A. Linley and S. Joseph, Eds., pp. 388-404, John Wiley \& Sons, Hoboken, NJ, USA, 2004.

[25] C. R. Snyder, S. C. Sympson, F. C. Ybasco, T. F. Borders, M. A. Babyak, and R. L. Higgins, "Development and validation of the State Hope Scale," Journal of Personality and Social Psychology, vol. 70, no. 2, pp. 321-335, 1996.

[26] C. R. Snyder, J. Cheavens, and S. T. Michael, "Hoping," in Coping: The Psychology of What Works, C. R. Snyder, Ed., pp. 205-231, Oxford University Press, New York, NY, USA, 1999.

[27] D. McDermott and C. R. Snyder, The Great Big Book of Hope: Help Your Children Achieve Their Dreams, New Harbinger Publications, Oakland, Calif, USA, 2000.

[28] S. J. Lopez, J. Bouwkamp, L. E. Edwards, and J. Teramoto Pedrotti, "Making hope happen via brief interventions," in Proceedings of the 2 nd Positive Psychology Summit, Washington, DC, USA, October 2000.

[29] E. C. Chang, "Hope, problem-solving ability, and coping in a college student population: some implications for theory and practice," Journal of Clinical Psychology, vol. 54, no. 7, pp. 953 962, 1998.

[30] L. A. Curry, S. D. Maniar, K. A. Sondag, and S. Sandstedt, "An optimal performanceacademic course for university students and student-athletes," Unpublished manuscript, University of Montana, Missoula, Mont, USA, 1999.

[31] L. A. Curry, C. R. Snyder, D. L. Cook, B. C. Ruby, and M. Rehm, "Role of hope in academic and sport achievement," Journal of Personality and Social Psychology, vol. 73, no. 6, pp. 1257-1267, 1997.

[32] A. J. Onwuegbuzie and C. R. Snyder, "Relations between hope and graduate students' coping strategies for studying and examination-taking," Psychological Reports, vol. 86, no. 3, pp. 803-806, 2000.

[33] C. R. Snyder, H. S. Shorey, J. Cheavens, K. M. Pulvers, V. H. Adams III, and C. Wiklund, "Hope and academic success in college," Journal of Educational Psychology, vol. 94, no. 4, pp. 820-826, 2002.

[34] C. R. Snyder, "Hope and optimism," in Encyclopedia of Human Behavior, V. S. Ramachandran, Ed., vol. 2, pp. 535-542, Academic Press, San Diego, Calif, USA, 1994.

[35] G. D. Kuh, T. M. Cruce, R. Shoup, J. Kinzie, and R. M. Gonyea, "Unmasking the effects of student engagement on first-year college grades and persistence," Journal of Higher Education, vol. 79 , no. 5 , pp. 540-563, 2008.
[36] R. Gilman, J. Dooley, and D. Florell, "Relative levels of hope and their relationship with academic and psychological indicators among adolescents," Journal of Social and Clinical Psychology, vol. 25, no. 2, pp. 166-178, 2006.

[37] C. R. Snyder, S. S. Ilardi, J. Cheavens, S. T. Michael, L. Yamhure, and S. Sympson, "The role of hope in cognitivebehavior therapies," Cognitive Therapy and Research, vol. 24, no. 6, pp. 747-762, 2000. 


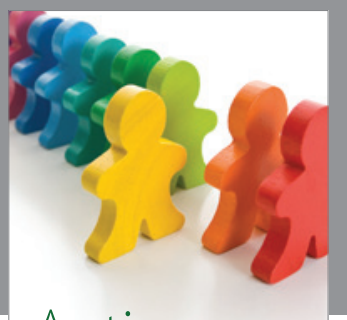

Autism

Research and Treatment
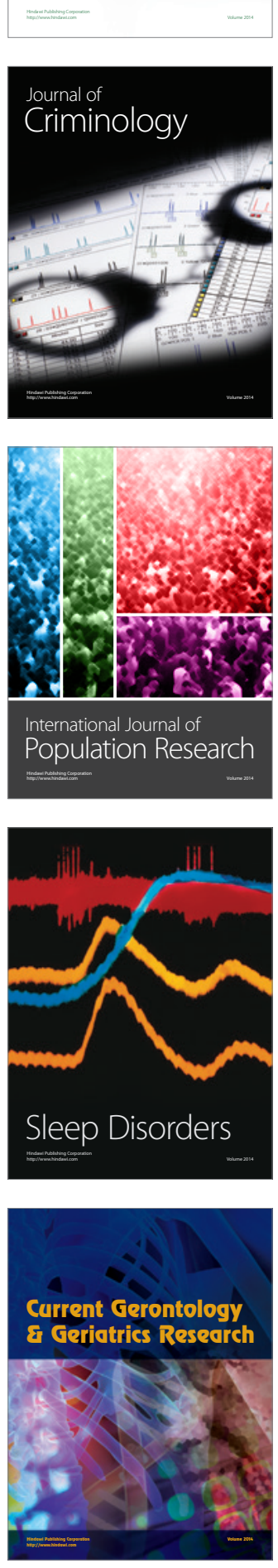
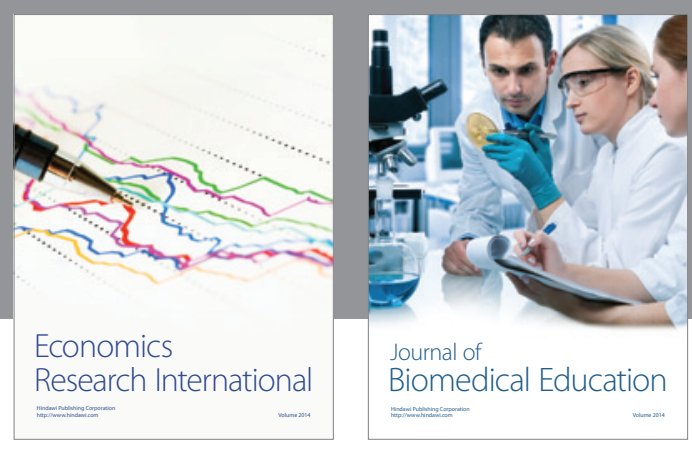

Journal of

Biomedical Education

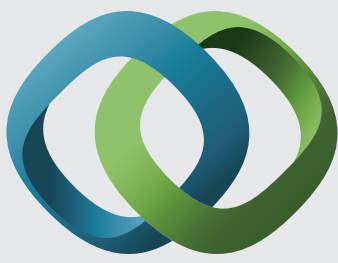

\section{Hindawi}

Submit your manuscripts at

http://www.hindawi.com
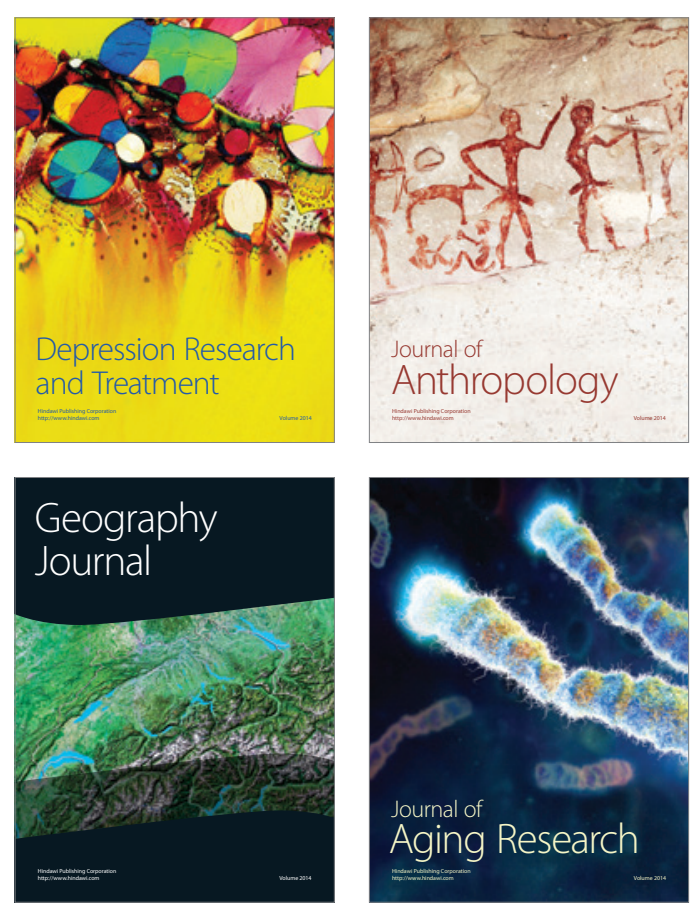

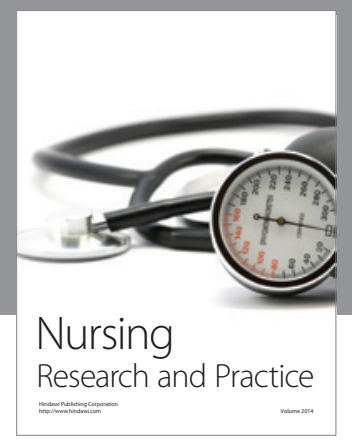

Nursing

Research and Practice

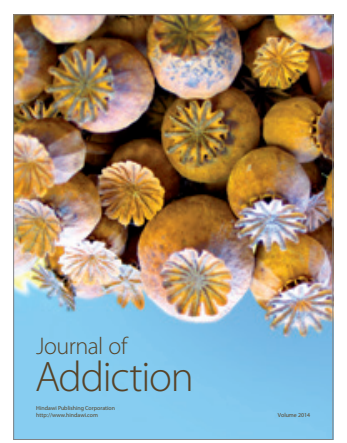

Child Development

Research

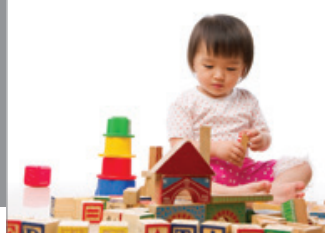

迥
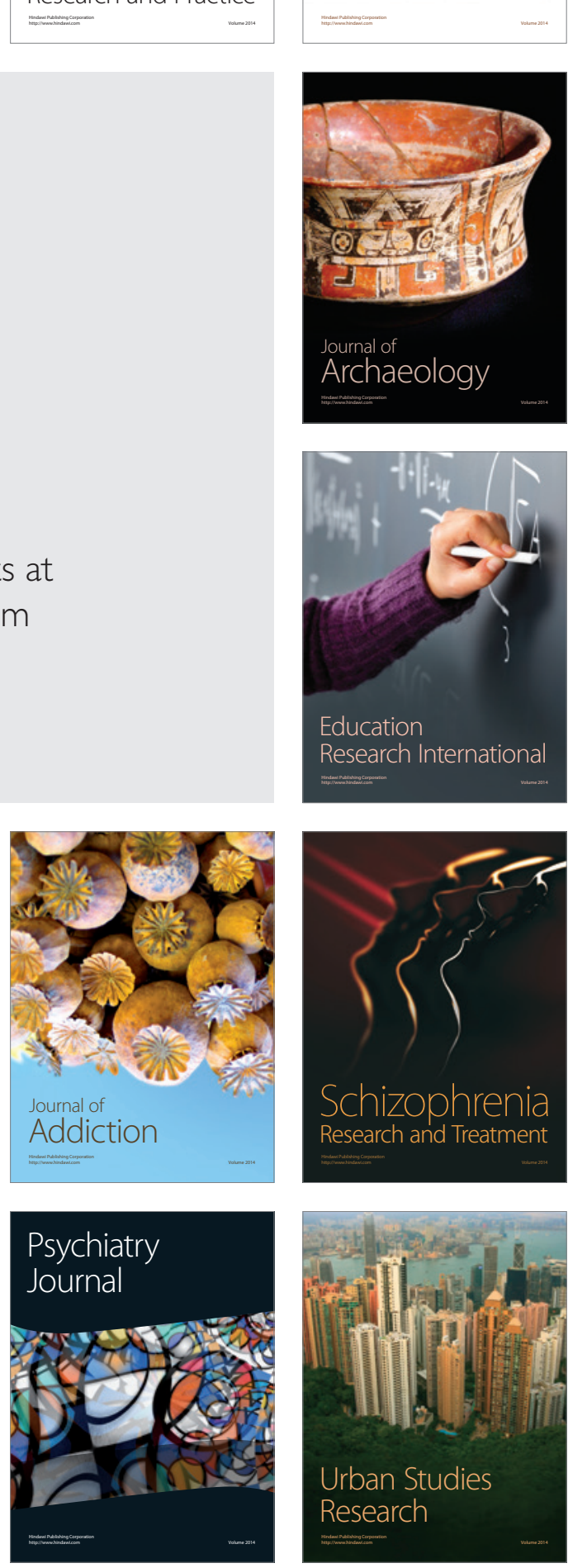